\title{
Possible role of intravenous administration of mesenchymal stem cells to alleviate interstitial cystitis/bladder pain syndrome in a Toll-like receptor-7 agonist-induced experimental animal model in rat
}

Hidetoshi Tabata ${ }^{1}$, Masanori Sasaki ${ }^{2,3,4^{*}}$, Yuko Kataoka-Sasaki ${ }^{2}$, Nobuo Shinkai ${ }^{1}$, Koji Ichihara ${ }^{1}$, Naoya Masumori ${ }^{1}$, Jeffery D. Kocsis ${ }^{3,4}$ and Osamu Honmou 2,3,4

\begin{abstract}
Background: Interstitial cystitis/bladder pain syndrome (IC/BPS) categorized with and without Hunner lesions is a condition that displays chronic pelvic pain related to the bladder with no efficacious treatment options. There are strong associations suggested between Hunner-type IC and autoimmune diseases. Recently, we established an animal model of Hunner-type IC using a Toll-like receptor-7 (TLR7) agonist. Intravenous infusion of mesenchymal stem cells (MSCs) can be used to treat injury via multimodal and orchestrated therapeutic mechanisms including anti-inflammatory effects. Here, we investigated whether infused MSCs elicit therapeutic efficacy associated with the TLR7-related anti-inflammatory pathway in our Hunner-type IC model.

Methods: Voiding behaviors were monitored $24 \mathrm{~h}$ prior to the Loxoribine $(L X)$, which is a TLR7 agonist instillation in order to establish a Hunner-type IC model (from - 24 to $0 \mathrm{~h}$ ) in female Sprague-Dawley rats. LX was instilled transurethrally into the bladder. At $0 \mathrm{~h}$, the initial freezing behavior test confirmed that no freezing behavior was observed in any of the animals. The LX-instilled animals were randomized. Randomized LX-instilled rats were intravenously infused with MSCs or with vehicle through the right external jugular vein. Sampling tissue for green fluorescent protein (GFP)-positive MSCs were carried out at $48 \mathrm{~h}$. Second voiding behavior tests were monitored from 72 to $96 \mathrm{~h}$. After the final evaluation of the freezing behavior test at $96 \mathrm{~h}$ after $\mathrm{LX}$ instillation (72 $\mathrm{h}$ after MSC or vehicle infusion), histological evaluation with H\&E staining and quantitative real-time polymerase chain reaction (RT-PCR) to analyze the mRNA expression levels of inflammatory cytokines were performed.
\end{abstract}

Results: Freezing behavior was reduced in the MSC group, and voiding behavior in the MSC group did not deteriorate. Hematoxylin-eosin staining showed that mucosal edema, leukocyte infiltration, and hemorrhage were suppressed in the MSC group. The relative expression of interferon- $\beta$ mRNA in the bladder of the MSC group was

\footnotetext{
*Correspondence: msasaki@sapmed.ac.jp

${ }^{2}$ Department of Neural Regenerative Medicine, Research Institute

for Frontier Medicine, Sapporo Medical University School of Medicine,

Sapporo, Hokkaido 060-8556, Japan

Full list of author information is available at the end of the article
}

(C) The Author(s) 2021. Open Access This article is licensed under a Creative Commons Attribution 4.0 International License, which permits use, sharing, adaptation, distribution and reproduction in any medium or format, as long as you give appropriate credit to the original author(s) and the source, provide a link to the Creative Commons licence, and indicate if changes were made. The images or other third party material in this article are included in the article's Creative Commons licence, unless indicated otherwise in a credit line to the material. If material is not included in the article's Creative Commons licence and your intended use is not permitted by statutory regulation or exceeds the permitted use, you will need to obtain permission directly from the copyright holder. To view a copy of this licence, visit http://creativecommons.org/licenses/by/4.0/. The Creative Commons Public Domain Dedication waiver (http://creativecommons.org/publicdomain/zero/1.0/) applies to the data made available in this article, unless otherwise stated in a credit line to the data. 
inhibited. Numerous GFP-positive MSCs were distributed mainly in the submucosal and mucosal layers of the inflammatory bladder wall.

Conclusion: Intravenous infusion of MSCs may have therapeutic efficacy in a LX-instilled Hunner-type IC rat model via a TLR7-related anti-inflammatory pathway.

Keywords: Intravenous, Mesenchymal stem cell, Hunner-type interstitial cystitis

\section{Background}

Interstitial cystitis/bladder pain syndrome (IC/BPS) is a condition that causes chronic pelvic pain related to the bladder with no efficacious treatment options [1]. The complete picture of IC/BPS remains unclear; however, IC/BPS can be categorized into IC/BPS with and without Hunner lesions [2]. Hunner-type IC is characterized by the cystoscopic finding known as Hunner lesions, reddish mucosal lesions accompanied by abnormal capillary structures. Hunner-type IC has a proven bladder histology that manifests epithelial denudation and chronic inflammatory changes, such as lymphoplasmacytic and mast cell infiltration, stromal fibrosis, and edema [3].

Recently, we established an animal model of Hunnertype IC using a Toll-like receptor 7 (TLR7) agonist [4]. Strong associations occur between Hunner-type IC and autoimmune diseases [5]. Toll-like receptors (TLRs) are key players in the innate immune system and in biological defense mechanisms against external pathogens [6]. Among TLRs, TLR7 is associated with the development and maintenance of inflammation and pain and is considered to contribute to the development of several autoimmune diseases [5]. As we identified an increase in the number of TLR7 immunoreactive cells and in TLR7 mRNA expression in the bladder of Hunner-type IC patients, loxoribine (LX) (a TLR7 agonist) was applied to the bladder of C57BL/6N female mice to induce edema, congestion and inflammation and was associated with significantly increased TLR7-mRNA expression (4). The animals instilled with LX demonstrated increased licking behavior, voiding frequency, and afferent nerve activities associated with increased single-voided volume and intercontraction interval of micturition per cystometry measurements [4].

Cellular therapy for IC/BPS, using mesenchymal stem cells (MSCs) derived from multiple sources, has been reported to provide therapeutic efficacy. The proposed mechanisms by which transplanted MSCs restrain IC/ BPS symptoms include regeneration of damaged bladder tissue through the Wnt pathway [7, 8], anti-tissue fibrosis [9], anti-apoptosis via the AKT/mTOR pathway [10], antioxidant [11, 12], and anti-inflammatory effects including mast cell infiltration and inhibition of inflammatory cytokines [13, 14]. However, specific pathways inhibiting inflammation in MSCs have not been identified.

Here, we investigated whether intravenous infusion of MSCs elicits therapeutic efficacy to reduce inflammation in our established Hunner-type IC model with a TLR7 agonist. Bladder pain-like behavior and voiding behaviors were monitored. In addition, histopathological gene expression analyses was carried out to identify a TLR7related anti-inflammatory pathway, with the intent of utilizing these data to develop approaches to reduce the symptoms in this experimental Hunner-type IC model.

\section{Materials and methods \\ Preparation of MSCs from bone marrow}

MSCs were cultured as described in our previous studies $[15,16]$. Briefly, the bone marrow was collected from the femoral bones of adult wild-type Sprague-Dawley (SD) rats and GFP-expressing rats [W-Tg (CAGGFP)184Ys], diluted to $25 \mathrm{ml}$ with Dulbecco's modified Eagle's medium (DMEM) (Sigma, St. Louis, MO, USA), supplemented with $10 \%$ heat-inactivated fetal bovine serum (FBS) (Thermo Fisher Scientific Inc., Waltham, MA, USA), $2 \mathrm{mM}$ l-glutamine (Sigma), $100 \mathrm{U} / \mathrm{ml}$ penicillin, and $0.1 \mathrm{mg} / \mathrm{ml}$ streptomycin (Thermo Fisher Scientific Inc.), and incubated for 3 days $\left(5 \% \mathrm{CO}_{2}, 37{ }^{\circ} \mathrm{C}\right)$. When the cultures almost reached confluence (over 95\%), adherent cells were detached using trypsin-EDTA solution (Sigma) and subcultured on a $150 \mathrm{~mm}^{2}$ tissue culture dish (1030-150: IWAKI, Tokyo, Japan; surface area: 148 $\left.\mathrm{cm}^{2}\right)$ at $5 \times 10^{5}$ cells $/ \mathrm{ml}$ in $14 \mathrm{ml}$ culture medium; thus, the plating density was approximately $3.4 \times 10^{3} / \mathrm{cm}^{2}$. The surface antigen phenotype of MSCs was as follows: $\mathrm{CD} 45^{-}, \mathrm{CD} 3^{+}, \mathrm{CD} 90^{+}$, and $\mathrm{CD} 106^{-}[17,18]$. The cultured MSCs were used for infusion after three passages. For infusion, the supernatants discarded and MSCs $\left(1.0 \times 10^{6}\right.$ cells $)$ were resuspended in fresh $1 \mathrm{ml}$ DMEM and injected.

\section{Hunner-type IC model}

Sixty-two female SD rats, aged 8 weeks, were used. The animals were housed under standard laboratory conditions with a 12:12 h light: dark cycle and free access to food and water. Under anesthesia with ketamine and xylazine (75 and $10 \mathrm{mg} / \mathrm{kg}$, respectively; i.p.), a polyethylene catheter (PE-50) was atraumatically inserted 
into the bladder of rats, transurethrally. After urine was drained, $200 \mu \mathrm{l}$ of $4.5 \mathrm{mM}$ Loxoribine (LX) (AdipoGen Life Sciences, Liestal, Switzerland) $(\mathrm{n}=36)$, a selective TLR7agonist [or distilled water (DW) for sham $(\mathrm{n}=14)$ ], was instilled slowly. The catheter was kept for $60 \mathrm{~min}$, after which the instilled liquid was drained, and the animals were allowed to recover from anesthesia.

\section{Experimental protocol}

The experimental protocol is illustrated in Fig. 1. Voiding behaviors (1) were monitored $24 \mathrm{~h}$ prior to LX or DW instillation, to establish a Hunner-type IC model (from -24 to $0 \mathrm{~h}$ ). At $0 \mathrm{~h}$, the initial freezing behavior (1) test confirmed that no freezing behavior was observed in any of the animals (Fig. 2a). LX was instilled into 48 rats, and DW was instilled into 14 rats. After the second freezing behavior (2) test following LX or DW instillation at $24 \mathrm{~h}$, the $12 \mathrm{LX}$-instilled rats that displayed no freezing behavior were excluded. Thus, we included 36 LX-instilled rats and $14 \mathrm{DW}$-instilled rats for this study. Eight of the $36 \mathrm{LX}$-instilled rats were used for the detection of GFPexpressing MSCs (GFP-MSCs). GFP-MSCs were infused into LX-instilled animals $(\mathrm{n}=4)$, and MSCs derived from wild-type animals were infused into LX-instilled animals $(\mathrm{n}=4)$, at $48 \mathrm{~h}$ ( $24 \mathrm{~h}$ after MSC or vehicle infusion). The remaining LX-instilled animals $(n=28)$ were randomized. Randomized LX-instilled rats were intravenously infused with MSCs (MSC group: $1.0 \times 10^{6}$ cells in $1 \mathrm{ml}$ fresh DMEM) or with vehicle (Vehicle group: $1 \mathrm{ml}$ fresh DMEM), and the DW-instilled rats were infused with vehicle only (Sham group) through the right external jugular vein [15]. Second voiding behavior [2] tests were

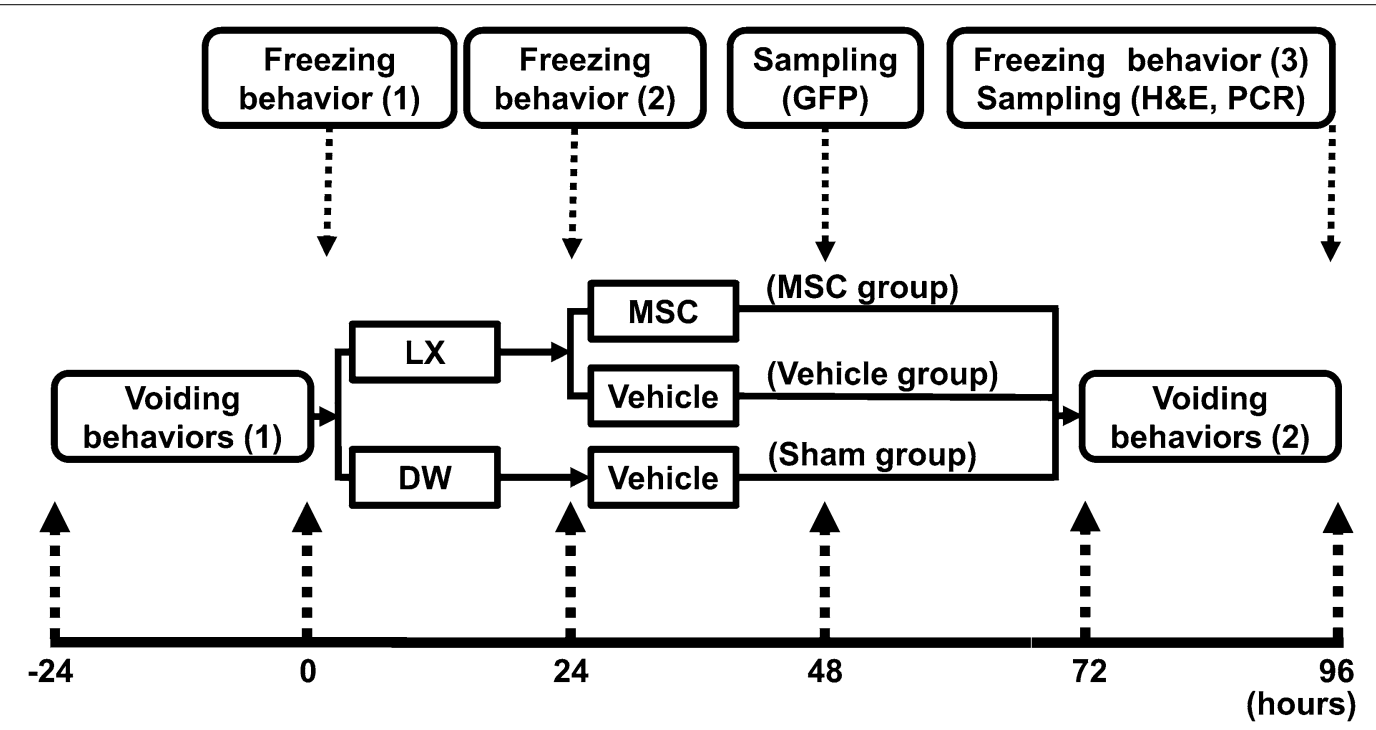

Fig. 1 Experimental protocol
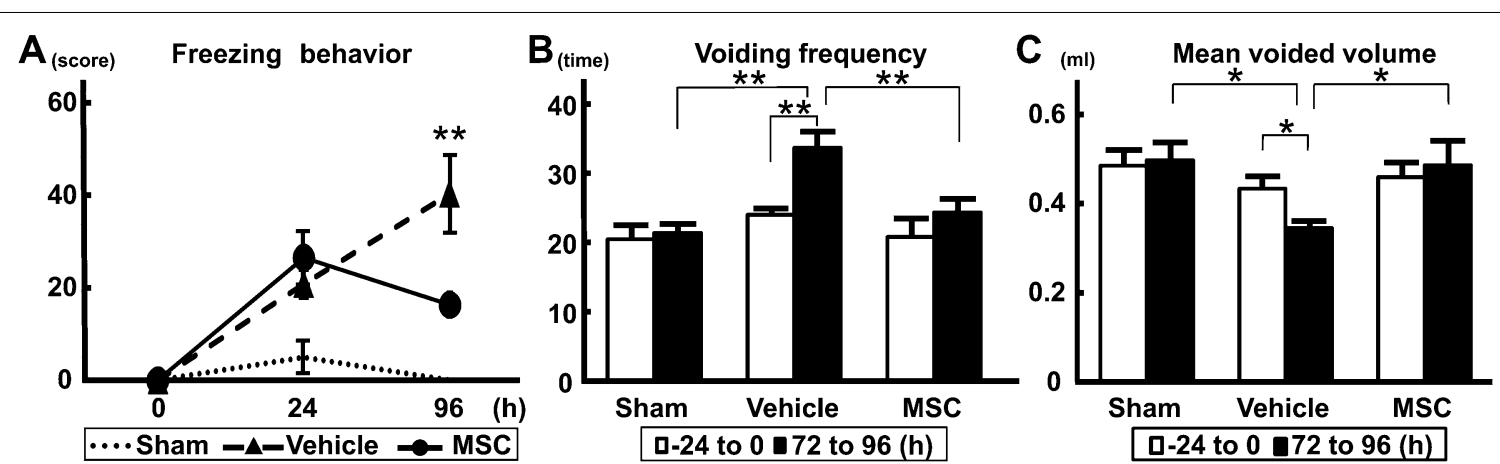

Fig. 2 Urological evaluations. a Bladder pain-like behavior; b voiding frequency; c mean voided volume. $n=6 / g r o u p$. ANOVA with the TukeyKramer post hoc test. ${ }^{*} p<0.05,{ }^{* *} p<0.01$. $h$ "hour" 
monitored from 72 to $96 \mathrm{~h}$. After the final evaluation of the freezing behavior [3] test at $96 \mathrm{~h}$ after LX instillation (72 $\mathrm{h}$ after MSC or vehicle infusion), histologic evaluations and quantitative real-time polymerase chain reaction (RT-PCR) were performed.

\section{Transplantation procedure}

The rats used in this study were anesthetized with an intraperitoneal (IP) injection of ketamine and xylazine $(90 / 4 \mathrm{mg} / \mathrm{kg})$ and received intravenous infusion of MSCs $\left(1.0 \times 10^{6}\right)$ in $1.0 \mathrm{ml}$ total fluid volume $(\mathrm{DMEM})$ or vehicle $(1.0 \mathrm{ml}$ fresh DMEM alone) via right external jugular vein. All rats were injected subcutaneously daily with cyclosporine A (10 mg/kg).

\section{Freezing behavior}

Freezing behavior was defined as bladder pain-like behavior of rats, indicated by cessation of movement and pointing of the nose toward the lower abdomen without licking. If the freezing behavior occurred within a 5-s interval, it was scored as one positive event. The number of positive events of the respective behaviors was counted for $30 \mathrm{~min}$ [19].

\section{Voiding behavior}

Voiding behaviors (voiding frequency and measurement of voided volume) were recorded for $24 \mathrm{~h}$ using a metabolic cage (Urination Monitor-100, Melquest Ltd., Toyama, Japan), after $24 \mathrm{~h}$ of adaptation to the environment [4]. The voiding frequency was recorded for $24 \mathrm{~h}$; after a 5-min interval, it was defined as the next voiding. The cutoff for voided volume in this experiment was defined as $0.03 \mathrm{ml}$. These settings were applied according to the findings from our pilot study. During recording, the rats were allowed free access to water and food.

\section{Histopathological analyses}

Rats were deeply anesthetized with an intraperitoneal injection of ketamine $(50 \mathrm{mg} / \mathrm{kg})$ and xylazine $(10 \mathrm{mg} /$ $\mathrm{kg}$ ), perfused with phosphate-buffered saline (PBS) and $4 \%$ paraformaldehyde (PFA) in $0.1 \mathrm{M}$ phosphate-buffer (PB), $96 \mathrm{~h}$ after LX instillation (72 $\mathrm{h}$ after MSC or vehicle infusion). Then, the bladders were isolated from each group and opened at the dorsal side of the bladder neck, along the midline towards the dome. After macroscopic evaluation, bladders were placed in $4 \%$ formaldehyde and embedded in paraffin for microscopic evaluation via hematoxylin-eosin (H\&E) staining. For H\&E staining, paraffin-embedded sections were cut $(3 \mu \mathrm{m})$ using a Leica RM2265 microtome (Leica Microsystems, Wetzlar, Hesse-Darmstadt, Germany). The deparaffinized sections were stained with hematoxylin for $5 \mathrm{~min}$ at room temperature, followed by staining with eosin solution
$(1 \%$ eosin $+95 \%$ ethanol + acetate $)$ for $3 \mathrm{~min}$ at room temperature and then photographed (BZ-9000; Keyence, Osaka, Japan). During histological evaluation, ten fields of each slide were scored for mucosal edema, leukocyte infiltration, hemorrhage, and mucosal abrasion [20]. Edema was evaluated at $\times 200$ magnification. No edema was scored as 0 , minimal edema (no change in connective tissue thickness) as 1, moderate edema (connective tissue thickness increased by $<$ twofold) as 2, and severe edema (connective tissue thickness increased by $>$ twofold) as 3. Leukocyte infiltration was evaluated in the mucosa at $\times 400$ magnification. No extravascular leukocytes were scored as $0,>20$ leukocytes as 1, 20-45 leukocytes as 2 , and $>45$ leukocytes as 3 . Mucosal hemorrhage and mucosal abrasion were evaluated at $\times 100$ magnification. The presence of hemorrhage and mucosal abrasion was scored as 1 , and no change was scored as 0 . The total score of all fields of view for mucosal edema, leukocyte infiltration, mucosal hemorrhage, and mucosal abrasion was divided by the maximum possible score and then multiplied by 100 [20].

\section{RT-PCR}

Quantitative RT-PCR was performed as previously described [15]. After $96 \mathrm{~h}$ of LX instillation (72 h after MSC or vehicle infusion), the animals were anesthetized with an intraperitoneal injection of ketamine $(50 \mathrm{mg} / \mathrm{kg})$ and xylazine $(10 \mathrm{mg} / \mathrm{kg})$, and bladders from each group were collected using a dissecting microscope. Total RNA was extracted using an RNeasy Plus Mini kit (\#74134, Qiagen, Valencia, CA, USA) according to the manufacturer's instructions. The RNA concentration was quantified by determining the optical density at $260 \mathrm{~nm}$. RNA $(1 \mu \mathrm{g})$ was reverse transcribed into cDNA using SuperScript III reverse transcriptase (Qiagen) and oligo-dT. Real-time PCR for each sample was performed in triplicate with TaqMan Universal Master Mix II with no UNG (Thermo Fisher Scientific Inc.). The following sets of specific primers and TaqMan probes were purchased from Thermo Fisher Scientific Inc.: glyceraldehyde3-phosphate dehydrogenase (GAPDH) (TaqMan rodent GAPDH control reagents, Rn01775763-g1) as an endogenous control, and TLR7 (Rn01771083) and interferon $(I F N)-\beta$ (Rn00569434) as target genes. The reactions were run on an ABI-StepOne real-time PCR system (Thermo Fisher Scientific Inc.) using a 48-well plate format. The cycling conditions included an initial denaturation phase at $95{ }^{\circ} \mathrm{C}$ for $3 \mathrm{~min}$, followed by 40 cycles of $95{ }^{\circ} \mathrm{C}$ for $15 \mathrm{~s}$ and $55^{\circ} \mathrm{C}$ for $60 \mathrm{~s}$. Relative quantification of target gene expression was performed using the comparative threshold cycle method, according to the manufacturer's guidelines. 


\section{Detection of GFP expressing MSCs}

Detection of GFP expressing MSCs was performed as previously described [15]. One day after injection of GFP-MSCs from GFP-expressing rats and non-GFPMSCs from wild-type SD rats, transcardial perfusion (4\% PFA) under anesthesia with an intraperitoneal injection of ketamine $(50 \mathrm{mg} / \mathrm{kg})$ and xylazine $(10 \mathrm{mg} / \mathrm{kg})$ was performed to dissect out the bladder. After dissection, the bladders were fixed in $4 \%$ PFA for $1 \mathrm{~h}$ at $4{ }^{\circ} \mathrm{C}$. Then, the frozen embedded bladder was cut into $12-\mu \mathrm{m}$ thick sections with a cryostat and mounted on glass slides. Slides were washed thrice in PBS with Tween 20 (0.1\%) (PBST) and blocked in normal goat serum (10\%) and Triton X $(0.3 \%)$ in PBS at room temperature for $30 \mathrm{~min}$. The sections were then incubated overnight at $4{ }^{\circ} \mathrm{C}$ with the primary antibody (chicken anti-GFP antibody, 1:1000; ab13970, Abcam, Cambridge, MA, USA), diluted with normal goat serum (5\%), Triton X (0.3\%), and PBS. After four washes in PBST, the sections were incubated with the secondary antibody (1:2000; AF 488-conjugated goat anti-chicken immunoglobulin Y, Abcam, 150,173) for $1 \mathrm{~h}$ and counterstained with DAPI. The sections were then examined using a confocal microscope (Ex/Em, 405/488: LSM780 ELYRA system; Carl Zeiss, Oberkochen, Germany).

\section{Statistical analysis}

All statistical analyses were performed using SPSS 18 (SPSS Inc., Chicago, IL, USA). Comparisons were performed using one-way analysis of variance with the Tukey-Kramer post hoc test.

\section{Results}

The freezing behavior score was decreased following MSC infusion

There were no significant differences among the three experimental groups (MSC, vehicle, and sham) in the initial freezing behavior (1) test at $0 \mathrm{~h}$. At $24 \mathrm{~h}$ after LX or DW instillation (prior to MSC or vehicle infusion), the scores of the second freezing behavior (2) test were increased in the LX-instilled groups (both vehicle and MSC groups). At $96 \mathrm{~h}$, the freezing behavior score was further increased in the vehicle group; however, the score in the MSC group decreased $(p<0.01)$ (Fig. 2a).

\section{The intravenous infusion of MSCs suppressed pelvic pain evaluated with voiding behaviors}

There were no significant differences among the three groups in terms of voiding frequency (Fig. 2b) and mean voided volume (Fig. $2 \mathrm{c}$ ) from -24 to $0 \mathrm{~h}(p=0.55)$. It was difficult to measure stable voiding behaviors prior to MSC or vehicle infusion, possibly because of the effects of anesthesia and intravesical activity of catheter implantation for instillation of LX into the bladder. In addition, a $24 \mathrm{~h}$ period is required to measure voiding behaviors (see Materials and Methods). The voiding frequency in the vehicle group at $96 \mathrm{~h}$ (from 72 to $96 \mathrm{~h}$ ) was elevated compared with that in the MSC and sham groups $(p<0.01)$; there was no difference between the sham and MSC-infused groups. The voiding frequency at $96 \mathrm{~h}$ was also higher than that at $0 \mathrm{~h}$ (from -24 to $0 \mathrm{~h}$ ) in the vehicle group, although there were no differences between the sham and MSC-infused groups. The mean voided volume in the vehicle group at $96 \mathrm{~h}$ (from 72 to $96 \mathrm{~h}$ ) was lower than that in the MSC and sham groups $(p<0.05)$, and there was no difference between the sham and MSC-infused groups. The mean voided volume at $96 \mathrm{~h}$ was lower than that at $0 \mathrm{~h}$ (from -24 to $0 \mathrm{~h}$ ) in the vehicle group, although there was no difference between the sham and MSC-infused groups. These results suggest that intravenous infusion of MSCs suppressed pelvic pain following LX instillation in the bladder, indicating the therapeutic efficacy of infused MSCs for experimental IC.

\section{Intravenous infusion of MSCs inhibited histopathological damage}

Macroscopic observation revealed that the bladder wall in the vehicle group (Fig. 3b) was thicker than that in the sham group (Fig. 3a), and the bladder wall in the MSC group (Fig. 3c) was thinner than that in the vehicle group. Histopathological evaluation using H\&E staining in the vehicle group revealed mucosal edema (Fig. 3e), mucosal ablation (Fig. 3e, red arrows), hemorrhage (Fig. 3h, green arrow), and leukocyte infiltration (Fig. 3h, blue arrows), although H\&E staining in the sham group (Fig. 3d, g) showed no thickening and edema in the mucosal and submucosal layers, as well as no inflammatory features such as hemorrhage or leukocyte infiltration. In the vehicle group, these inflammatory features were less observed compared to the MSC group (Fig. 3f, i). Mucosal edema (Fig. 4a, $p<0.01$ ), leukocyte infiltration (Fig. $4 \mathrm{~b}: p<0.05$ ), and hemorrhage (Fig. 4c, $p<0.05$ ) were evident in the vehicle group after LX instillation compared with the sham group. These changes were suppressed in the MSCtreated group. Although a trend was observed, there were no significant differences among the three groups in mucosal ablation (Fig. $4 \mathrm{~d}, p=0.16$ ). These results indicate that intravenous infusion of MSCs inhibited histopathological damage following LX instillation in the bladder.

\section{Infused MSCs reduced the expression of IFN- $\beta$ in the TLR7 expressed bladder wall following $L X$ instillation}

The relative expression of TLR7-mRNA in the bladder wall in both vehicle and MSC groups was elevated following LX instillation compared with the sham group (Fig. 5a: $p<0.01$ ), and there was no significant difference 


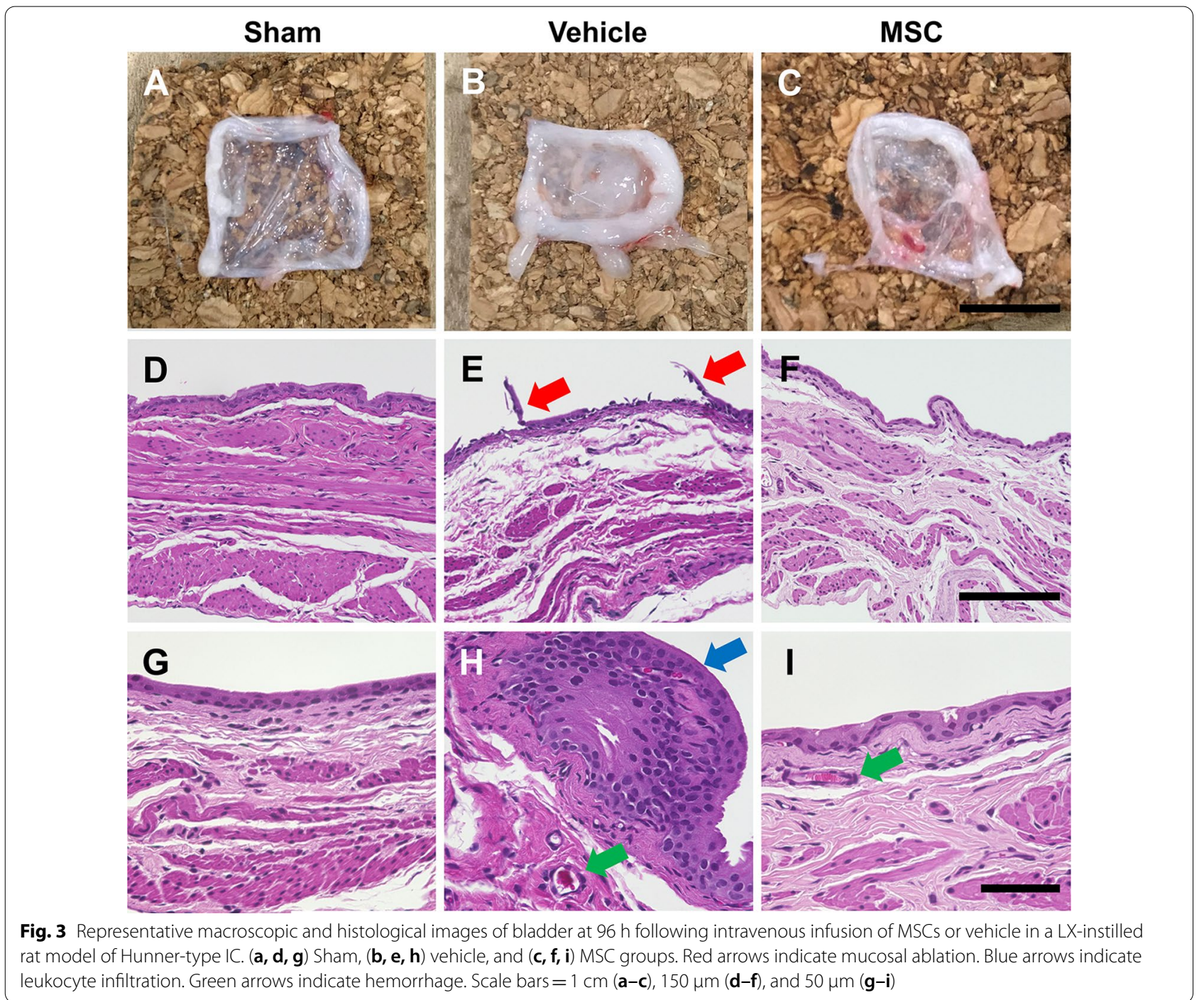

between the MSC and vehicle groups. The relative expression of IFN- $\beta$ mRNA in the bladder wall in the vehicle group was elevated following LX instillation compared with that in the MSC and sham groups (Fig. 5b, $p<0.05)$. Even though TLR7 levels were elevated in the MSC group after LX instillation, IFN- $\beta$ mRNA levels were not.

\section{Accumulated MSCs in the inflammatory bladder wall} GFP-MSCs were identified in the inflammatory bladder wall via observation of green fluorescence (Fig. 6a). Numerous infused GFP-MSCs were more extensively distributed in the submucosal and mucosal layers and few GFP-MSCs were present in the muscle layer (Fig. 6a). The accumulation of the infused GFP-MSCs demonstrated a homing effect in the LX-instilled bladder, suggesting that GFP-MSCs might accumulate at the inflammation lesion site in the bladder, where we observed leukocyte infiltration in the vehicle group (Fig. 3h). To confirm whether the infused MSCs showed autofluorescence at the wavelengths used to study GFP fluorescence, we examined sections of samples from animals infused with non-GFP-MSCs derived from wild-type SD rats. No $\mathrm{GFP}^{+}$cells were observed in these rats (Fig. 6b).

\section{Discussion}

We found that intravenous infusion of MSCs reduced the symptoms of IC/BPS in our newly established animal model of Hunner-type IC using a TLR7 agonist. The IC/ BPS related freezing behavior was improved (reduced), and the voiding behaviors scored as voiding frequency and mean voided volume did not deteriorate following infusion of MSCs compared with the vehicle group. Macroscopic observation and histological analysis using $H \& E$ staining demonstrated that preservation of the bladder wall structure was clearly observed in the MSC 

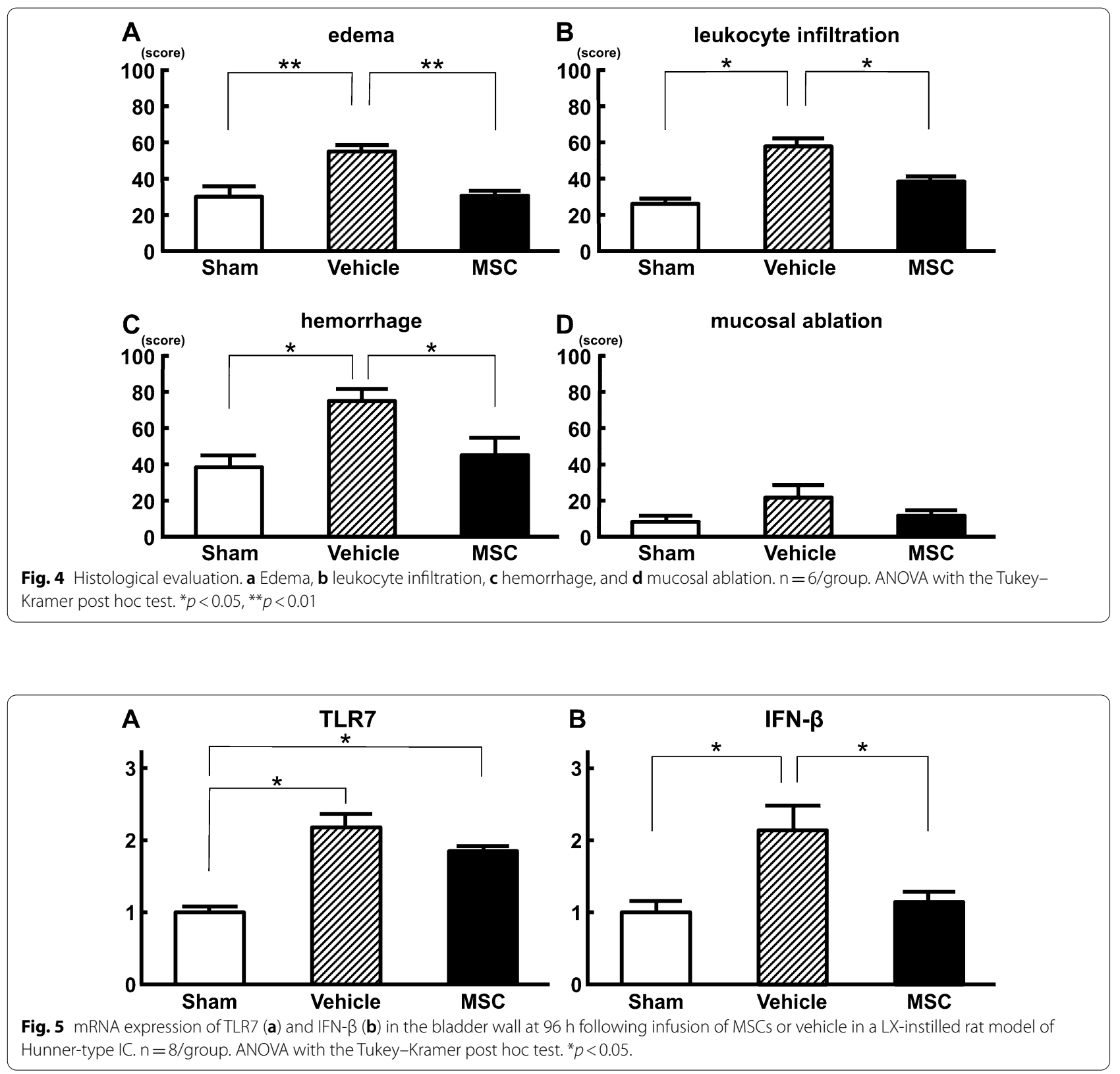

group. The bladder wall thickness in the MSC group was thinner than that in the vehicle group, and several pathological features, including hemorrhage, edema, and leukocyte infiltration, showed improvement in bladder wall pathology. We observed a significantly higher expression of TLR7 mRNA in the bladder wall in our IC/BPS model. However, the expression of IFN- $\beta$ mRNA in the MSC group was significantly reduced compared to that in the vehicle group. Accumulated GFP-MSCs were found mainly in the submucosal and mucosal layers in the inflammatory bladder wall after intravenous infusion of GFP-MSCs. These data suggest that MSCs might contribute to the downregulation of IFN- $\beta$ and thus reduction in inflammation.

Although the etiology and pathophysiology of IC/ BPS are uncertain, autoimmune disorders are common comorbidities of IC/BPS [21]. Thus, autoimmunity could be among the possible causes of IC/BPS [22]. In the animal model of Hunner-type IC induced by a TLR7 agonist used here [4], we elucidated that intravenous infusion of MSCs provides therapeutic efficacy for the Hunner-type IC model by downregulating the expression of IFN- $\beta$ in a TLR7-induced rat model. Previous studies indicated that TLR7-myeloid differentiation primary response 88 


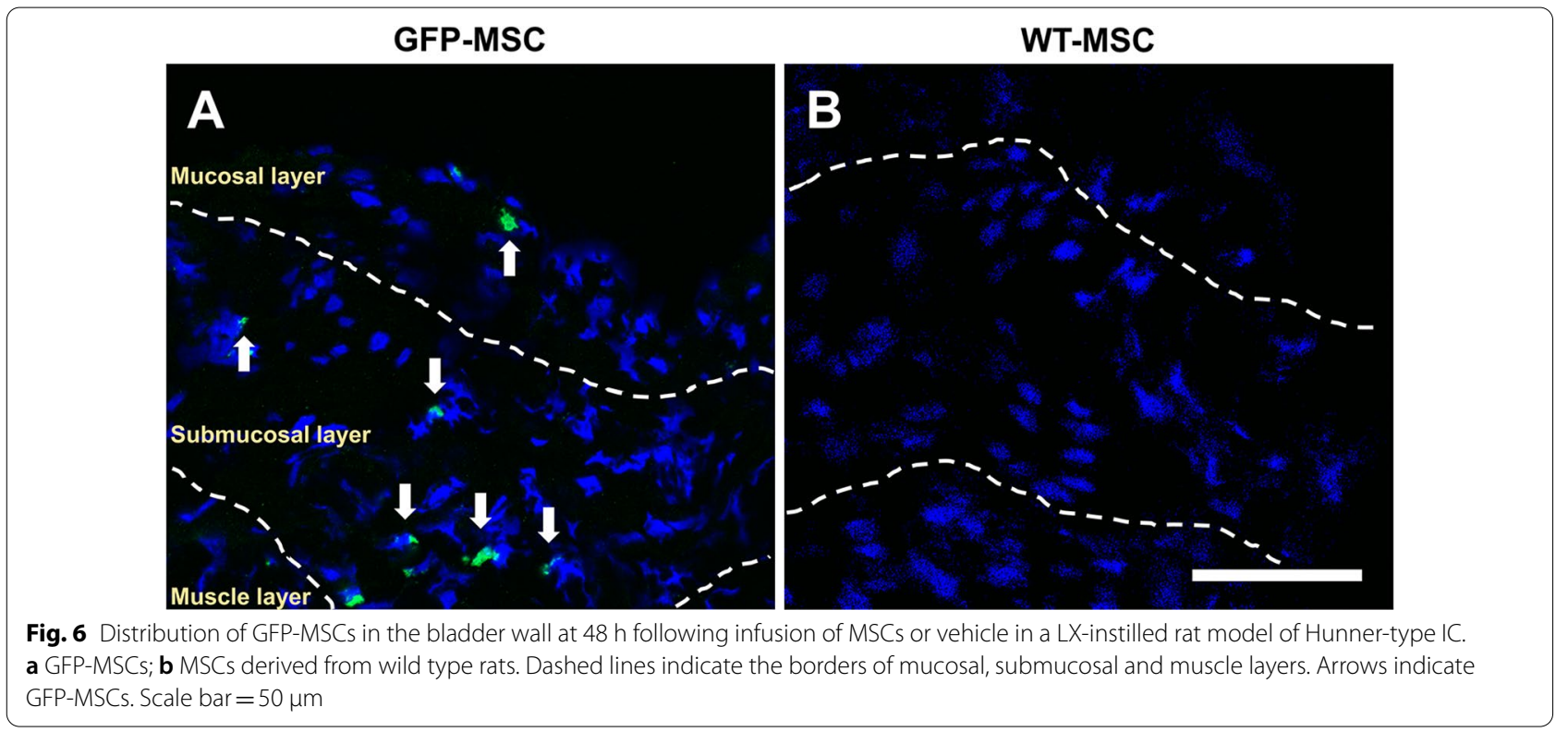

(MyD88) signaling, which activates interferon regulatory factor 7 (IRF-7), results in robust induction of IFN- $\beta$ [23, 24]. It has been reported that MSCs secrete transforming growth factor beta (TGF- $\beta$ ) [25] and they can stimulate macrophages to secrete TGF- $\beta$ in sites of inflammation [26]. Infused MSCs accumulated in the mucosal and submucosal layers of the bladder wall and might contribute to increased levels of TGF- $\beta$ [25]. TGF- $\beta$ inhibits the phosphorylation of IRF-7, reduces the protein level of MyD88 [27], and downregulates the production of IFN- $\beta$ [28]. The expression level of TLR7 was not significantly reduced in our model system, although $I F N-\beta$ was downregulated following intravenous infusion of MSCs. Therefore, it is conceivable that infused MSCs might play an important role in reducing the expression of IFN- $\beta$ (Fig. 7), thereby promoting the reduction of inflammation in the bladder wall. Thus, a novel finding of this study is that the intravenous infusion of MSCs has therapeutic effects on Hunner-type IC by downregulating the expression of IFN- $\beta$ in this TLR7-induced Hunner-type IC model. Therefore, using this unique model, a novel pathway for inhibiting the inflammation induced by infused MSCs has been proposed.

It is important to contextualize that Ichihara et al. used mice to develop this Hunner-type IC model with TLR7; however, we used rats because most cellular transplantation studies with Hunner-type IC models have used rats [7-10, 13, 14, 29]. We used the same concentration of LX as that in the mouse model $(4.5 \mathrm{mM}, 100 \mu \mathrm{m})$ [4], but we increased the volume of LX $(4.5 \mathrm{mM}, 200 \mu \mathrm{m})$ in the current study after considering the bladder volume of rats [30]. A potential

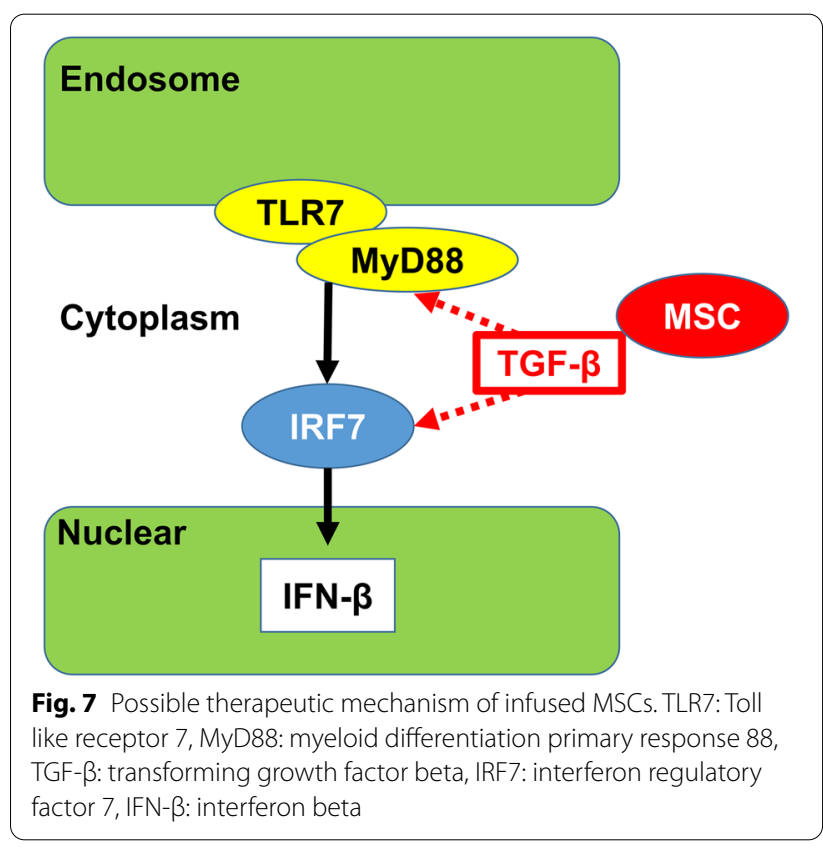

strength of this study is the use of a TLR7-induced Hunner-type IC rat model system compared with other commonly used IC/BPS model systems induced with cyclophosphamide [31, 32], lipopolysaccharide [33], hydrochloric acid $(\mathrm{HCl})[7,13]$, uroplakin $[14,29]$ and ketamine [9].

We propose that the TLR7-related anti-inflammatory pathway is associated with restraining IC/BPS pathology. This study provides additional insights into the anti-inflammatory mechanism of infused MSCs, in 
addition to the infiltration of mast cells and reduction of inflammatory cytokines [13, 14].

A limitation of this study is that as mentioned above, that we employed the methods used in the original paper by Ichihara et al. [4]. The study period by Ichihara et al. was $96 \mathrm{~h}$ which we used in this study. We also would like to stress that our preliminary study with our established Hunner-type IC model with TLR7 agonist demonstrated that the bladder pain-like behavior and voiding behaviors did not last more than a week. Thus, we focused on acute therapeutic effects of infused MSCs in this study. We also realize that elucidation of the precise molecular mechanism underlying the MSC therapy is important and future studies should be performed to establish a more appropriate model for longer term study and study of corresponding pathways and proteins using western blot and ELISA.

\section{Conclusions}

Intravenous infusion of MSCs may have an impact on the mitigation of IC/BPS symptoms via IFN- $\beta$ downregulation in a TLR7-induced rat model of Hunner-type IC model system.

\section{Acknowledgements}

We thank the National BioResource Project-Rat (http://www.anim.med. kyoto-u.ac.jp/NBR/) for providing the strain of rats used in the current study [W-Tg (CAG-GFP) 184Ys].

\section{Authors' contributions}

HT: Protocol development, data collection, data analysis. MS: Project development, data analysis and management, and manuscript writing. YKS: Project development, data analysis. NS: Protocol development. KI: Protocol development, manuscript editing. NM: Project development, data analysis, manuscript editing. JDK: Data analysis, manuscript writing. $\mathrm{OH}$ : Project development, data analysis, management, manuscript writing. All authors read and approved the final manuscript.

\section{Funding}

This work was supported in part by JSPS KAKENHI, a Grant-in Aid for Scientific Grant-in Aid for Scientific Research (C) to H.T (18K09199) and the Merit Review Award 1101 BX003190 from the U.S Department of Veterans Affairs BLRD and the RRD Services.

\section{Availability of data and materials}

The datasets used and/or analyzed during the current study are available from the corresponding author on reasonable request.

\section{Declarations}

Ethics approval and consent to participate

All experiments were performed in accordance with the institutional guidelines of the Sapporo Medical University. The use of animals in this study was approved by the Animal Care and Use Committee of Sapporo Medical University. The study was carried out in compliance with the ARRIVE guidelines.

\section{Consent for publication}

Not applicable.

\section{Competing interests}

The authors declare that they have no competing interests.

\section{Author details}

'Department of Urology, Sapporo Medical University School of Medicine, Sapporo 060-8556, Japan. ${ }^{2}$ Department of Neural Regenerative Medicine, Research Institute for Frontier Medicine, Sapporo Medical University School of Medicine, Sapporo, Hokkaido 060-8556, Japan. ${ }^{3}$ Department of Neurology, Yale University School of Medicine, New Haven, CT 06510, USA. ${ }^{4}$ Center for Neuroscience and Regeneration Research, VA Connecticut Healthcare System, West Haven, CT 06516, USA.

Received: 11 August 2021 Accepted: 8 November 2021

Published online: 13 November 2021

\section{References}

1. Ko KJ, Cho WJ, Lee YS, Choi J, Byun HJ, Lee KS. Comparison of the efficacy between transurethral coagulation and transurethral resection of hunner lesion in interstitial cystitis/bladder pain syndrome patients: a prospective randomized controlled trial. Eur Urol. 2020;77(5):644-51.

2. van de Merwe JP, Nordling J, Bouchelouche P, Bouchelouche K, Cervigni M, Daha LK, et al. Diagnostic criteria, classification, and nomenclature for painful bladder syndrome/interstitial cystitis: an ESSIC proposal. Eur Urol. 2008;53(1):60-7.

3. Akiyama Y, Luo Y, Hanno PM, Maeda D, Homma Y. Interstitial cystitis/bladder pain syndrome: the evolving landscape, animal models and future perspectives. Int J Urol. 2020;27(6):491-503.

4. Ichihara K, Aizawa N, Akiyama Y, Kamei J, Masumori N, Andersson KE, et al. Toll-like receptor 7 is overexpressed in the bladder of Hunner-type interstitial cystitis, and its activation in the mouse bladder can induce cystitis and bladder pain. Pain. 2017;158(8):1538-45.

5. Andersson KE, Birder L. Current pharmacologic approaches in painful bladder research: an update. Int Neurourol J. 2017;21(4):235-42.

6. Iwasaki A, Medzhitov R. Regulation of adaptive immunity by the innate immune system. Science. 2010;327(5963):291-5.

7. Song M, Lim J, Yu HY, Park J, Chun JY, Jeong J, et al. Mesenchymal stem cell therapy alleviates interstitial cystitis by activating wnt signaling pathway. Stem Cells Dev. 2015;24(14):1648-57.

8. Ryu CM, Yu HY, Lee HY, Shin JH, Lee S, Ju H, et al. Longitudinal intravital imaging of transplanted mesenchymal stem cells elucidates their functional integration and therapeutic potency in an animal model of interstitial cystitis/bladder pain syndrome. Theranostics. 2018;8(20):5610-24.

9. Kim A, Yu HY, Heo J, Song M, Shin JH, Lim J, et al. Mesenchymal stem cells protect against the tissue fibrosis of ketamine-induced cystitis in rat bladder. Sci Rep. 2016;6:30881.

10. Xie J, Liu B, Chen J, Xu Y, Zhan H, Yang F, et al. Umbilical cord-derived mesenchymal stem cells alleviated inflammation and inhibited apoptosis in interstitial cystitis via AKT/mTOR signaling pathway. Biochem Biophys Res Commun. 2018;495(1):546-52.

11. Chen YT, Chiang HJ, Chen CH, Sung PH, Lee FY, Tsai TH, et al. Melatonin treatment further improves adipose-derived mesenchymal stem cell therapy for acute interstitial cystitis in rat. J Pineal Res. 2014;57(3):248-61.

12. Shin JH, Ryu CM, Ju H, Yu HY, Song S, Shin DM, et al. Synergistic effects of $\mathrm{N}$-acetylcysteine and mesenchymal stem cell in a lipopolysaccharideinduced interstitial cystitis rat model. Cells. 2019;9(1):86.

13. Furuta A, Yamamoto T, Igarashi T, Suzuki Y, Egawa S, Yoshimura N. Bladder wall injection of mesenchymal stem cells ameliorates bladder inflammation, overactivity, and nociception in a chemically induced interstitial cystitis-like rat model. Int Urogynecol J. 2018;29(11):1615-22.

14. Chung JW, Chun SY, Lee EH, Ha YS, Lee JN, Song PH, et al. Verification of mesenchymal stem cell injection therapy for interstitial cystitis in a rat model. PLoS ONE. 2019;14(12):e0226390.

15. Matsuda Y, Sasaki M, Kataoka-Sasaki Y, Takayanagi A, Kobayashi K, Oka S, et al. Intravenous infusion of bone marrow-derived mesenchymal stem cells reduces erectile dysfunction following cavernous nerve injury in rats. Sex Med. 2017.

16. Takemura M, Sasaki M, Kataoka-Sasaki Y, Kiyose R, Nagahama H, Oka $\mathrm{S}$, et al. Repeated intravenous infusion of mesenchymal stem cells provides enhanced functional recovery in a rat model of chronic cerebral ischemia. J Neurosurg. (in press). 
17. Kim S, Honmou O, Kato K, Nonaka T, Houkin K, Hamada H, et al. Neural differentiation potential of peripheral blood-and bone-marrow-derived precursor cells. Brain Res. 2006;1123(1):27-33.

18. Ukai R, Honmou O, Harada K, Houkin K, Hamada H, Kocsis J. Mesenchymal stem cells derived from peripheral blood protects against ischemia. J Neurotrauma. 2007;24(3):508-20.

19. Saitoh C, Chancellor MB, de Groat WC, Yoshimura N. Effects of intravesical instillation of resiniferatoxin on bladder function and nociceptive behavior in freely moving, conscious rats. J Urol. 2008;179(1):359-64.

20. Dönmez M, İnci K, Zeybek ND, Doğan HS, Ergen A. The Early histological effects of intravesical instillation of platelet-rich plasma in cystitis models. Int Neurourol J. 2016;20(3):188-96.

21. Homma Y, Akiyama Y, Tomoe H, Furuta A, Ueda T, Maeda D, et al. Clinical guidelines for interstitial cystitis/bladder pain syndrome. Int J Urol. 2020;27(7):578-89.

22. Bosch PC. A randomized, double-blind, placebo-controlled trial of certolizumab pegol in women with refractory interstitial cystitis/bladder pain syndrome. Eur Urol. 2018;74(5):623-30.

23. Kawai T, Sato S, Ishii KJ, Coban C, Hemmi H, Yamamoto M, et al. Interferon-alpha induction through Toll-like receptors involves a direct interaction of IRF7 with MyD88 and TRAF6. Nat Immunol. 2004;5(10):1061-8.

24. Honda K, Yanai H, Mizutani T, Negishi H, Shimada N, Suzuki N, et al. Role of a transductional-transcriptional processor complex involving MyD88 and IRF-7 in Toll-like receptor signaling. Proc Natl Acad Sci USA. 2004;101(43):15416-21.

25. Nakazaki M, Oka S, Sasaki M, Kataoka-Sasaki Y, Onodera R, Komatsu K, et al. Prevention of neointimal hyperplasia induced by an endovascular stent via intravenous infusion of mesenchymal stem cells. J Neurosurg. 2019;6:1-13.

26. Nakazaki M, Morita T, Lankford KL, Askenase PW, Kocsis JD. Small extracellular vesicles released by infused mesenchymal stromal cells target M2 macrophages and promote TGF- $\beta$ upregulation, microvascular stabilization and functional recovery in a rodent model of severe spinal cord injury. J Extracell Vesicles. 2021;10(11):e12137.
27. Naiki Y, Michelsen KS, Zhang W, Chen S, Doherty TM, Arditi M. Transforming growth factor-beta differentially inhibits MyD88-dependent, but not TRAM- and TRIF-dependent, lipopolysaccharide-induced TLR4 signaling. J Biol Chem. 2005;280(7):5491-5.

28. Naiki Y, Komatsu T, Koide N, Dagvadorj J, Yoshida T, Arditi M, et al. TGF- $\beta 1$ inhibits the production of IFN in response to CpG DNA via ubiquitination of TNF receptor-associated factor (TRAF) 6. Innate Immun. 2015;21(7):770-7

29. Kim BS, Chun SY, Lee EH, Chung JW, Lee JN, Ha YS, et al. Efficacy of combination therapy with pentosan polysulfate sodium and adipose tissue-derived stem cells for the management of interstitial cystitis in a rat model. Stem Cell Res. 2020;45:101801.

30. Ito Y, Kashiwabara M, Yoshida A, Hikiyama E, Onoue S, Yamada S. Muscarinic receptor binding in rat bladder urothelium and detrusor muscle by intravesical solifenacin. Biol Pharm Bull. 2016;39(7):1167-71.

31. Taidi Z, Mansfield KJ, Bates L, Sana-Ur-Rehman H, Liu L. Purinergic P2X7 receptors as therapeutic targets in interstitial cystitis/bladder pain syndrome; key role of ATP signaling in inflammation. Bladder (San Franc). 2019;6(1):e38

32. Augé C, Gamé X, Vergnolle N, Lluel P, Chabot S. Characterization and validation of a chronic model of cyclophosphamide-induced interstitial cystitis/bladder pain syndrome in rats. Front Pharmacol. 2020;11:1305.

33. Kogan P, Xu S, Wang Y, O'Donnell MA, Lutgendorf SK, Bradley CS, et al. Sub-noxious intravesical lipopolysaccharide triggers bladder inflammation and symptom onset in a transgenic autoimmune cystitis model: a MAPP network animal study. Sci Rep. 2018;8(1):6573.

\section{Publisher's Note}

Springer Nature remains neutral with regard to jurisdictional claims in published maps and institutional affiliations.
Ready to submit your research? Choose BMC and benefit from:

- fast, convenient online submission

- thorough peer review by experienced researchers in your field

- rapid publication on acceptance

- support for research data, including large and complex data types

- gold Open Access which fosters wider collaboration and increased citations

- maximum visibility for your research: over $100 \mathrm{M}$ website views per year

At BMC, research is always in progress.

Learn more biomedcentral.com/submissions 